\title{
DOE/CH/11239-Final
}

Georgia Tech Research Corporation

\section{Carpet As An Alternative Fuel in Cement Kilns}

\author{
$\underline{\text { Principle Investigator }}$ \\ Dr. Matthew J Realff \\ School of Chemical \&Biomolecular Engineering \\ Georgia Institute of Technology \\ Team Member \\ Lehigh Cement Company \\ Project Partners \\ CarpetCycle llc, Dave Zwicky \& Sons, Republic Machine, \\ Carpet \& Rug Institute, EPA, \\ ASME Research Committee Energy, Environment and Waste.
}

\section{FINAL REPORT}




\section{Table of Contents}

Main Report

I. Executive Summary

II. Comparison of Goals \& Objectives to Actual Accomplishments

III. Summary of the Project Activities

IV. Supporting Introductory Information

V. Project Results

VI. VI. Products Developed

Appendix A - Dave Zwicky \& Sons System Setup

Appendix B - Lehigh Feed System Jam

Appendix C - Details of Size Reduction Machine Design 


\section{List of Figures}

Figure 1 Carpet Constructions Tufted Carpet (left) and Level Loop Carpet (right)

Figure 2 Overall Economics as a Function of Landfill Tip Fee for the Average Case of other costs and values.

\section{List of Tables}

Table 1 SB Latex Carpet Representative Composition

Table 2 Broadloom End Use

Table 3 Synthetic Carpet Fiber Shipments 2005

Table 4 Carpet Recycling Volume and Composition Assumptions

Table 5 Lbs of carpet available per year by face fiber type.

Table 6 Specific Emission Category Measurements and Tests

Table 7 Run Date, Fuel and Duration

Table 8 Summary of Particulate Emissions Results, these are averages of two runs for coal and three runs for carpet.

Table 9 Summary of NOX and SOX emissions.

Table 10 Base Case Economic Assumption Values

Table 11 Overall Supply Operating Costs

Table 12 Best, Average and Worst Cases for Economics of Carpet as a Fuel

Table 13 Size Reduction Cost Components Base Case. 


\section{Executive Summary}

Approximately 5 billion lbs of carpet will be removed from buildings in the US each year for the foreseeable future. This carpet is potentially a valuable resource because it contains plastic in the face of the carpet that can be re-used. However, there are many different types of carpet, and at least four major different plastics used to make the face. The face is woven through a backing fabric and held in place by a "glue" that is in most cases a latex cross-linked polymer which is heavily loaded with chalk (calcium carbonate). This backing has almost no value as a recycled material. In addition, carpet is a bulky material that is difficult to handle and ship and must be kept dry. It would be of significant benefit to the public if this stream of material could be kept out of landfills and some of its potential value unlocked by having high volume alternatives for recycled carpet use.

The research question that this project investigated was whether carpet could be used as a fuel in a cement kiln. If this could be done successfully, there is significant capacity in the US cement industry to absorb carpet and use it as a fuel. Cement kilns could serve as a way to stimulate carpet collection and then side streams be taken for higher value uses. The project sought to develop and test components of a system to do this at full scale for a trial period. The goal was to establish that the emissions from burning the carpet would not cause problems, and that the carpet could be technically and economically converted into a fuel suitable for a cement kiln. Any system to turn carpet into a fuel would require three separate problems to be solved. First, the carpet would have to be collected and shipped to the cement kiln for processing into a fuel. Second, the carpet would have to be turned into a suitable physical form to be fed at high and reliable flowrates to the kiln. Third, the carpet would have to be fed to the kiln and the combustion conditions controlled to avoid any negative effects for the kiln and for the environment. All of these tasks would have to be done so that the overall economics of the system would be feasible.

The research demonstrated that carpet was technically a suitable fuel, but was unable to conclude that the overall system could be economically feasible at this time with the constraints placed on the project by using an existing system for feeding the kiln. Collection and transportation were relatively straightforward, using an existing collector who had the capacity to collect high volumes of material. The shredding of the carpet into a suitable form for feeding was more challenging, but these problems were successfully overcome. The feeding of the carpet into the kiln was not successfully carried out reliably. The existing system developed for wood chips did not work with the carpet and would jam unless closely supervised. Economically the various stages of the process turned out to be too costly, and the carpet ended up being more expensive as a fuel than would be justified. A particular issue was the risk that the kiln would have to take in order to implement the system, and its need to charge for the material on the basis of this risk. 


\section{Comparison of Goals \& Objectives to Actual Accomplishments}

\begin{tabular}{|c|c|c|}
\hline Original Project Goal & $\begin{array}{l}\text { \% of } \\
\text { Goal }\end{array}$ & Comments and any reasons for not achieving goal \\
\hline Technical Goals & $60 \%$ & $\begin{array}{l}\text { Individual goals given below. The most important } \\
\text { goals were achieved, secondary goals were not. }\end{array}$ \\
\hline $\begin{array}{l}\text { Develop a size reduction } \\
\text { machine suitable for high } \\
\text { throughput feed system to a } \\
\text { cement kiln. }\end{array}$ & $100 \%$ & $\begin{array}{l}\text { Two generations of designs were explored during } \\
\text { the project. The second generation machine was } \\
\text { very effective in achieving the goals needed for a } \\
\text { high throughput machine. }\end{array}$ \\
\hline $\begin{array}{l}\text { Develop a size reduction } \\
\text { system suitable for high } \\
\text { throughput feed system to a } \\
\text { cement kiln }\end{array}$ & $50 \%$ & $\begin{array}{l}\text { The lack of funding did not enable us to test the full } \\
\text { size reduction system that would have involved } \\
\text { automated materials handling systems. }\end{array}$ \\
\hline $\begin{array}{l}\text { Test feed system at Lehigh } \\
\text { for feeding carpet to a } \\
\text { cement kiln. }\end{array}$ & $75 \%$ & $\begin{array}{l}\text { We completed several days running on the system } \\
\text { and so tested the existing arrangement. We were } \\
\text { unable to establish the bounds on size reduction and } \\
\text { design parameters for a new system that would not } \\
\text { experience the difficulties of the existing system for } \\
\text { carpet. }\end{array}$ \\
\hline $\begin{array}{l}\text { Test emission profile of } \\
\text { carpet in a cement kiln and } \\
\text { compare it to that of coal as } \\
\text { a fuel. }\end{array}$ & $100 \%$ & $\begin{array}{l}\text { We completed several days of running with carpet } \\
\text { mixed into the fuel. This was sufficient to test the } \\
\text { emissions profile. We were able to test the } \\
\text { emissions without carpet, running on coal only and } \\
\text { so complete this component of the evaluation. }\end{array}$ \\
\hline $\begin{array}{l}\text { Test different fuel fractions } \\
\text { of carpet and possible } \\
\text { co-feeding strategies. }\end{array}$ & $0 \%$ & $\begin{array}{l}\text { We were unable to resume the trial after the first } \\
200 \text { tons of pure carpet were fed. Therefore we } \\
\text { were unable to test further mixtures of carpet and } \\
\text { wood as a more suitable fuel mix. }\end{array}$ \\
\hline $\begin{array}{l}\text { Feed } 1000 \text { tons of carpet to } \\
\text { cement kiln }\end{array}$ & $20 \%$ & $\begin{array}{l}\text { We fed } 200 \text { tons of carpet to the kiln over the period } \\
\text { of approximately } 1 \text { week. We were unable to feed } \\
\text { more carpet for several reasons, detailed in later } \\
\text { sections. }\end{array}$ \\
\hline Economic Goals & $25 \%$ & $\begin{array}{l}\text { We managed to evaluate many of the system } \\
\text { components, but we did not come up with a } \\
\text { convincing case for pursuing carpet as a fuel in } \\
\text { cement kilns. }\end{array}$ \\
\hline $\begin{array}{l}\text { Evaluate costs of size } \\
\text { reduction machine for carpet } \\
\text { as a fuel. }\end{array}$ & $80 \%$ & $\begin{array}{l}\text { Two generations of machines were built. The } \\
\text { second generation was tested for a short duration, } \\
\text { but not long enough to get data on the actual wear } \\
\text { characteristics of the knives by the abrasive carpet } \\
\text { system carpet. }\end{array}$ \\
\hline $\begin{array}{l}\text { Evaluate costs of delivery of } \\
\text { carpet as a fuel }\end{array}$ & $75 \%$ & $\begin{array}{l}\text { The delivery of carpet to the location was } \\
\text { thoroughly tested and we partially tested a system } \\
\text { for its conversion to a fuel. }\end{array}$ \\
\hline $\begin{array}{l}\text { Full system evaluation of } \\
\text { carpet as a fuel in cement } \\
\text { kilns. }\end{array}$ & $50 \%$ & $\begin{array}{l}\text { The feed system at the kiln was not suitable for } \\
\text { carpet as a fuel, it was designed for wood chips and } \\
\text { the differences were sufficient to cause operational } \\
\text { problems. Therefore we were unable to run }\end{array}$ \\
\hline
\end{tabular}




\begin{tabular}{|l|l|l|}
\hline & & $\begin{array}{l}\text { successfully for long enough to evaluate } \\
\text { performance. }\end{array}$ \\
\hline $\begin{array}{l}\text { Demonstrate economically } \\
\text { viable system for carpet as a } \\
\text { fuel in cement kilns. }\end{array}$ & $35 \%$ & $\begin{array}{l}\text { There were four major components of the system, } \\
\text { carpet collection/delivery, carpet size reduction, } \\
\text { carpet feeding, carpet combustion. We partially } \\
\text { demonstrated all of these, but did not run for } \\
\text { sufficient amounts to fully test the overall system. }\end{array}$ \\
\hline
\end{tabular}

\section{Summary of the Project Activities}

\section{A. Purpose of Trial \& Hypotheses}

The purpose of the trial was to test the use of carpet as a fuel in cement kilns at full scale but of temporary duration. There were several hypotheses that were to be tested during the trial along the supply chain from collection to combustion.

1. Carpet could be collected and delivered to a cement kiln economically from the NE Region of the United States.

2. Carpet could be size reduced for use in a cement kiln economically at a third party supplier of alternative fuels to the cement kiln. The trial was to gather data on size reduction to enable a full cost model of size reduction to be built.

3. Carpet could be successfully fed to a kiln using existing alternative fuel feed systems built for wood chips.

4. Carpet could be successfully combusted in the kiln and provide a significant (above 10\%) fraction of the cement kiln energy in a long dry kiln. The trial was to enable sufficiently long run of carpet to be attempted to show that a kiln could operate with carpet as a fuel.

5. The emissions from burning carpet would not be any worse that those from coal. The trial was to gather data on emissions necessary for pursuit of a permit from the Pennsylvania EPD. Nitrous oxide emissions were of specific concern due to the nitrogen content of the nylon in the carpet fiber.

\section{B. Main Findings}

The main findings of the trial were.

1) That carpet could be burnt in the kiln at rates that approximated about $10-15 \%$ of the fuel load of the long dry kiln.

2) That at this level of fuel substitution the carpet did not negatively impact the emissions from the kiln and may have had some positive effects in certain emissions quantities.

3) That the investment in the feed handling system at both the intermediate processor was inadequate for high throughput processing of the carpet and placed a lot of risk on machine damage due to foreign objects either in the carpet or picked up from the facility.

4) That the feed system at the kiln was inappropriate for handling carpet.

5) That the structure of having a collector, intermediate processor, and kiln consumer incurs very high overhead cost and double handling.

6) That the carpet burnt extremely well in the kiln, and as a result, the temperature profile in the kiln became close to operational limits.

7) That the size reduction system that was originally designed for the trial was inadequate because the carpet did not feed to the cutting zone in an efficient fashion

8) That the redesigned size reduction system was effective in reaching throughputs that were acceptable. 


\section{Supporting Introductory Information}

\section{A. Basic Carpet Information}

\section{Carpet Construction}

There are three major choices in carpet construction that have a significant influence on its use in cement kilns. First, there is a significant difference between carpet tile and broadloom carpet. Carpet tile is typically made for the commercial market place and has a significantly heavier backing than broadloom carpet. The backing is often made from PVC, and this is the dominant form in the market place today, although new backings are being introduced. PVC tiles are easily recognized and are currently handled through a recycling system either by Interface or by Tandus. Therefore they will not be considered any further in this report as they would never be considered as a fuel. The second carpet type, broadloom, is not recycled in significant volumes compared to its sales and is the subject of the report.

Broadloom carpets come in two varieties based on their backing type and the way the face fiber is introduced into the backing. The two backing types are a latex SB latex, and a polyurethane foam back. The two face fiber constructions are a level loop, where long strands of face fiber are woven into the backing parallel to the backing, and a tufted carpet, where the tufts are perpendicular to the backing and are individual hairpin loops with the bottom of the hairpin embedded in the carpet backing. The two different backing types influence the products of combustion from the kiln and also the melting points of the backing - which can influence the size reduction operation and its filler content which will influence the abrasiveness of the material in the size reduction process. The polyurethane backing will tend to melt if it gets too hot, the latex will not. The level loop carpet also influences the size reduction equipment performance. The long strands make the operation more difficult because they tend to wrap around the equipment rather than being cut. The tufted carpet does not present the same problems to the size reduction system. The tufted and level loop constructions are shown in Figure 1.
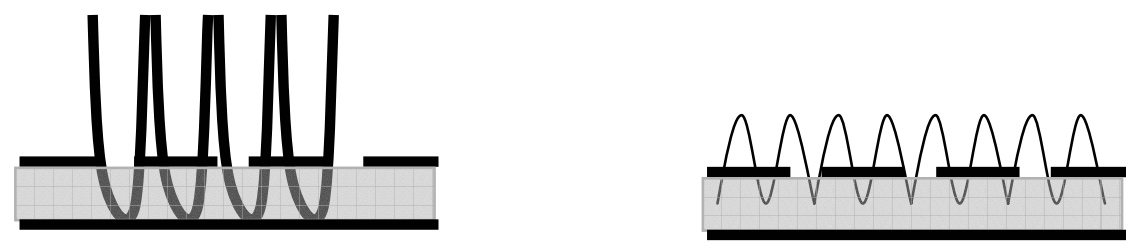

Figure 1 Carpet Constructions Tufted Carpet (left) and Level Loop Carpet (right)

The latex backed carpet has four main components; the face fiber, the primary backing layer, the filled latex glue layer, and the secondary backing layer. The main material differences occur in the face fiber, which is typically nylon 6, nylon 66, polypropylene, and smaller amounts of PET and wool faced carpets. The primary and secondary backings are polypropylene, and the latex styrene butadiene glue is typically filled with calcium carbonate, fly ash, or ground glass.

\section{Carpet Composition}

A typical SBL carpet composition is given in Table ??, as inputs to manufacturing to yield a $1.92 \mathrm{~kg} / \mathrm{sy}$ of final carpet. The face fiber has been chosen to be nylon 6 , but would be similar for other face yarn types. 


\begin{tabular}{|l|l|r|r|l|}
\hline $\begin{array}{l}\text { CAS } \\
\text { Number }\end{array}$ & Chemical & Amount & Final Product & Units \\
\hline \hline $1317-65-3$ & Calcium carbonate & 0.51 & 0.48 & {$[\mathrm{~kg} / \mathrm{sy}]$} \\
\hline $25038-54-4$ & Nylon 6 fiber & 0.86 & 0.81 & {$[\mathrm{~kg} / \mathrm{sy}]$} \\
\hline $25038-59-9$ & polypropylene & 0.19 & 0.18 & {$[\mathrm{~kg} / \mathrm{sy}]$} \\
\hline & $\begin{array}{l}\text { Aluminum } \\
21645-51-2\end{array}$ & 0.25 & 0.24 & {$[\mathrm{~kg} / \mathrm{sy}]$} \\
\hline & Sydroxide & 0.22 & 0.21 & {$[\mathrm{~kg} / \mathrm{sy}]$} \\
\hline & Stainblocker & $2.00 \mathrm{E}-04$ & $1.89 \mathrm{E}-04$ & {$[\mathrm{~kg} / \mathrm{sy}]$} \\
\hline & Other additives & $1.36 \mathrm{E}-03$ & $1.29 \mathrm{E}-03$ & {$[\mathrm{~kg} / \mathrm{sy}]$} \\
\hline & Total & 2.03 & 1.92 & {$[\mathrm{~kg} / \mathrm{sy}]$} \\
& & & & \\
\hline
\end{tabular}

Table 1 SB Latex Carpet Representative Composition

Source: SB Latex Carpet Life Cycle Inventory, Source: Dr. Michael Overcash.

\section{Carpet Market}

The following discussion is based on data presented in the July 17-31 issue 2005 of Floor Covering Weekly (FCW), which publishes annual statistics on the flooring industry. This is an annual survey that has been performed for 15 years and so has a significant history. It utilizes published government data as its starting point and data from the Fiber Economics Bureau. However, there is a significant amount of industry survey and customization that goes into refining the raw data. The statistics are produced by Floor Covering Weekly in conjunction with Catalina Research. There is no independent way to verify the accuracy of the statistics.

The total floor covering market was $\$ 24.15$ billion in wholesale for 2005 of which carpet and area rugs were 62.2\%. This represented a 3.9\% increase over 2004 and a total of $\$ 15$ billion. This comprised 19.27 billion sq feet at an average of $67 \%$ of the total square footage sold. This is an average value of $\$ 0.78$ per square foot, this has not changed significantly since 1997 when the dollar value per square foot was $\$ 0.70$.

The sales are divided into three main categories, residential, non-residential and other. The totals in these are $\$ 17.9$ billion, $\$ 5.29$ billion and $\$ 966$ million in the same wholesale dollars. The residential market is further subdivided into replacement and repair, new construction, and factory built housing, and the values are $\$ 13.5$ billion, $\$ 4.28$ billion and $\$ 120$ million respectively. Within the carpet and rug segment specifically the purchases can be subdivided both by category and by the type of face fiber. The carpet and rug segment splits into broadloom, modular and rug sales, and the broadloom and modular sales are the most significant from a replacement and recycling perspective. The data for the broadloom carpet, by end use, is presented in Table 2.

\begin{tabular}{|l|c|}
\hline Broadloom End Use & Wholesale Dollar Volume \% \\
\hline \hline Residential Consumer & 48.6 \\
\hline \multicolumn{1}{|c|}{ Replacement } & \multicolumn{2}{|c|}{35.4} \\
\hline \multicolumn{1}{|c|}{ Moved } & 13.2 \\
\hline \hline Commercial Contract & 24.7 \\
\hline Office & 9.2 \\
\hline Hospitality & 3.7 \\
\hline Health Care & 3.2 \\
\hline Education & 3.9 \\
\hline Retail & 3.7 \\
\hline
\end{tabular}




\begin{tabular}{|l|c|}
\hline Govt./Institutional & \multicolumn{1}{|c|}{2} \\
\hline \hline Residential Contract & 26.7 \\
\hline Single Family & 19 \\
\hline Multi-Family & 6.1 \\
\hline Manufactured Housing & 1.6 \\
\hline
\end{tabular}

Table 2 Broadloom End Use

Source: FCW

The second significant feature of the carpet shipments is the fiber type used to construct the carpet. This is significant because it affects the final value of the carpet from a recycling perspective as different face types are easier or more difficult to recycle and have higher or lower end market values. Table 3 has details of the synthetic carpet fiber shipments for 2005 , the total is 3.3 billion lbs of fiber.

\begin{tabular}{|l|l|}
\hline Carpet Fiber Type & \% of shipments (3.3 billion lbs total) \\
\hline \hline Nylon BCF & $43.8(1.4$ billon $)$ \\
\hline Polypropylene BCF & $21.9(700$ million) \\
\hline Nylon Staple & $18.7(600$ million) \\
\hline Polyester Staple & $12.5(400$ millon $)$ \\
\hline Polyester BCF & $3.1(100$ millon $)$ \\
\hline
\end{tabular}

Table 3 Synthetic Carpet Fiber Shipments 2005

Sources, Fiber Economics Bureau, FCW.

The most difficult issues in interpreting these statistics are that there is no information on the volume of fiber types by end-use category, and hence it is difficult to know what the actual fiber types are going down on to floors in different building use categories. However, there are some general heuristics that can be used to approximate these values. A secondary issue is that although the residential market is broken down by whether the carpet is being used for replacement or new construction, the same is not true for the commercial market segment.

The second issue, is that the current data is not representative of the carpet that is being pulled out of buildings today. For this we would need to project the composition of the carpet back to the time when it was being installed. This is somewhat complex because of the fact that the age distribution for when carpet is replaced is sensitive to the use category, region, and quite possibly the carpet construction itself.

\section{Carpet Recycling Volumes}

Carpet is essentially correlated to the buildings and occupancy types for a given region, but this data is not easy to obtain. Instead we use the most widely available data - the U.S. census combined with information published about carpet sales. A replacement rate is assumed: 2/3 of all carpet sold is for replacement. This, combined with the total sales for a given year, gives an estimate of the carpet volumes. The year 2005 is a good base to work from because of the availability of published sales data in [Floor Covering Weekly 2005]. The key issues are at what spatial scale the carpet sales data is available and whether there is any reason to assume replacement rates are different by region. We will use the following for the overall carpet flow estimation

\begin{tabular}{|l|l|}
\hline Data Category & \\
\hline US Population 2005 & 296.41 million \\
\hline Carpet Sales & 19.27 billion sq feet \\
\hline
\end{tabular}




\begin{tabular}{|l|l|l|}
\hline Carpet Weight & 64 oz/sq yard \\
\hline Replacement Percentage & $66 \%$ & $\%$ \\
\hline Removed Carpet Composition & Face Type & 30 \\
\cline { 2 - 3 } & Nylon 6 & 40 \\
\cline { 2 - 3 } & Nylon 66 & 20 \\
\cline { 2 - 3 } & Polypropylene & 10 \\
\cline { 2 - 3 } & PET and Other & 10 \\
\hline
\end{tabular}

Table 4 Carpet Recycling Volume and Composition Assumptions

This leads to the following estimates, in Table 5 , for the availability of carpet for recycling or alternative fuels based on the 2/3 replacement rate and the above fractions of face fiber types and the overall weight of a typical carpet.

\begin{tabular}{|c|c|c|}
\hline Face Type & Lbs/Year & erson \\
\hline N6 & $1.70 E+09$ & 5.72 \\
\hline N66 & $2.26 \mathrm{E}+09$ & 7.63 \\
\hline PP & $1.13 E+09$ & 3.81 \\
\hline PET Other & $5.65 E+08$ & 1.91 \\
\hline Total & $5.65 E+09$ & 19.1 \\
\hline
\end{tabular}

Table 5 Lbs of carpet available per year by face fiber type.

This is approximately $19 \mathrm{lbs} /$ person/year for all carpet fiber face types. This number can be used to estimate the availability of carpet in a given region based on its population.

\section{B. Basic Cement Kiln Information}

\section{Cement Manufacturing}

Limestone, clay, sand and a small amount of iron-containing materials are heated in a huge kiln at very high temperatures until they chemically combine to become modules called "clinker". The clinker is then mixed with gypsum and ground to a fine powder to make cement. Cement, in turn, is a key ingredient in concrete.

\section{Kiln Types}

There are several different types of kilns in operation today that reflect the history of cement kiln development. The most common configurations today are the long dry kiln and the pre-heater and pre-calciner types of kiln. In the long dry kiln, the cement raw materials are added at one end of the kiln and the fuel is burnt at the other end to provide all the energy input required for the chemical conversion of the feed and the heating requirements. In pre-heater kilns a certain percentage of the heat load is added at the same end of the kiln as the feed materials in order for them to reach a higher temperature before entering the kiln. In a pre-calciner kiln some of the initial reaction chemistry is also carried out in a tower preceding the kiln itself. Specifically the calcium carbonate is converted into calcium oxide. The advantage of this system is that up to $40 \%$ of the energy requirements can be added prior to the kiln itself, and at lower temperature, and hence the residence time in the kiln reduced, shortening the kiln.

\section{Lehigh Kiln.}

The Lehigh kiln studied in the trial is a long dry kiln which consumes about 10 tons/hr of coal in producing its clinker. The kiln is equipped with a fabric filter baghouse to collect particulates from the kiln exhaust gases. The dust is collected and recycled to the kiln. 


\section{Project Results}

The main results of the project fall into three categories, the emissions, the supply chain technical performance, and the supply chain economic performance. Each of these will be detailed below.

\section{Cement Kiln Emissions Assessment}

The full emissions report on the carpet co-fired with coal and coal only is provided in the EPA report, “Source Testing Final Report Fuel Comparison Coal Only and Carpet Co-Fire.” In this section the main results are summarized along with some hypotheses on why specific emission results were seen.

The emissions that were tested for as part of the trial were particulates, halogens, metals, dioxins/furans, sulfur dioxide, carbon monoxide, and nitrous oxides. The specifics of each of these categories are provided in Table 6.

\begin{tabular}{|l|l|l|}
\hline Emission Type & Specific Emission Category & Method (EPA) \\
\hline Particulate & Condensible, Filterable, PM $_{10}$ & CARB M501,M202-Hi \\
\hline Halogens & HCl, HF,Cl', Br & M5/26A \\
\hline $\begin{array}{l}\text { RCRA, CAA } \\
\text { Metals }\end{array}$ & $\begin{array}{l}\text { Sb,As,Ba,Cd,Cr,Co,Pb,Mn,Hg,Ni,Se } \\
\text {,Ag,Ti }\end{array}$ & M29 \\
\hline Gases & $\begin{array}{l}\text { Sulfur Dioxide, Nitrous Oxides, } \\
\text { Carbon Monoxide }\end{array}$ & M6C,M7E,M10 \\
\hline Dioxins/Furans & Oxygen, Carbon Dioxide & M23 \\
\hline $\begin{array}{l}\text { Gases (for Mwt } \\
\text { Calcs) }\end{array}$ & M3A \\
\hline
\end{tabular}

Table 6 Specific Emission Category Measurements and Tests

The tests were performed over a period of 6 days from Nov 8-Nov12th 2004. The runs on different days, the fuel type and duration are given in Table 7.

\begin{tabular}{|l|l|l|}
\hline Date & Kiln Fuel & Run Duration (nearest 10mins \\
\hline Nov 5 & Carpet co-fire & $4: 30$ \\
\hline Nov 8 & Carpet co-fire & $10: 20$ \\
\hline Nov 9 & Coal Only & $6: 50$ \\
\hline Nov 10 & Coal Only & $9: 40$ \\
\hline Nov 11 & Coal Only & $9: 00$ \\
\hline Nov 12 & Carpet co-fire & $8: 20$ \\
\hline
\end{tabular}

Table 7 Run Date, Fuel and Duration

The kiln was equipped with pollution control equipment in the form of a cyclone, spray tower, and fabric-filter baghouse, prior to the stack in which the sampling was performed. This had significant impact on the results. The particulate matter collected was extremely low for all runs, well below the recommended quantities that should be collected for the test method. This indicates the efficiency of the baghouse in preventing particulates of 10 microns in size from escaping. The results are therefore probably not very accurate.

\begin{tabular}{|l|l|l|l|}
\hline Particulates & Units & Coal Only & Carpet-Cofire \\
\hline Condensible Organic & $\mathrm{mg} / \mathrm{dscm}$ & 0.306 & 0.6 \\
\hline Condensible Inorganic & $\mathrm{mg} / \mathrm{dscm}$ & 219.2 & 91.9 \\
\hline Condensible Organic & $\mathrm{Lbs} / \mathrm{hr}$ & 0.0817 & 0.1401 \\
\hline Condensible Inorganic & $\mathrm{Lbs} / \mathrm{hr}$ & 58.6 & 22.3 \\
\hline
\end{tabular}




\begin{tabular}{|l|l|l|l|}
\hline Filterable Conc & $\mathrm{Mg} / \mathrm{dscm}$ & 1.55 & 1.15 \\
\hline Filterable Emissions & $\mathrm{Lbs} / \mathrm{hr}$ & 0.65 & 0.38 \\
\hline Total Particulate Conc & $\mathrm{mg} / \mathrm{dscm}$ & 221.1 & 93.2 \\
\hline Total Particulate Emssions & $\mathrm{Lbs} / \mathrm{hr}$ & 59.1 & 22.8 \\
\hline
\end{tabular}

Table 8 Summary of Particulate Emissions Results, these are averages of two runs for coal and three runs for carpet.

The results for carpet and coal are not considered to be significantly different, although the data suggest that the particulate emissions for carpet might be lower overall.

\begin{tabular}{|c|c|c|c|c|c|c|}
\hline Test data & Units & $\begin{array}{l}\text { Coal Only } \\
11 / 9-11 / 10\end{array}$ & $\begin{array}{l}\text { Coal Only } \\
11 / 10\end{array}$ & $\begin{array}{l}\text { Coal Only } \\
11 / 11\end{array}$ & \multicolumn{2}{|c|}{$\begin{array}{l}\text { Carpet } \\
\text { Co-Fire } \\
11 / 8\end{array}$} \\
\hline NOx & ppmvd & 1177 & 805 & 857 & 884 & 884 \\
\hline $\begin{array}{l}\text { Nox Emission } \\
\text { Rate }\end{array}$ & $\mathrm{Lb} / \mathrm{hr}$ & 452.3 & 285.1 & 323.8 & 355.7 & 339.2 \\
\hline $\begin{array}{l}\text { Nox Emission } \\
\text { Rate }\end{array}$ & $\begin{array}{l}\text { Lb/ton } \\
\text { clinker }\end{array}$ & 6.07 & 4.06 & 4.40 & 4.84 & 4.62 \\
\hline $\begin{array}{l}\text { Nox Allowed } \\
\text { Emission Rate }\end{array}$ & $\begin{array}{l}\text { Lb/ton } \\
\text { clinker }\end{array}$ & 8.83 & 8.83 & 8.83 & 8.33 & 8.33 \\
\hline $\mathrm{SO}_{2}$ Conc & ppmvd & 19.7 & 20.5 & 16.9 & 42.1 & 42.1 \\
\hline $\begin{array}{l}\mathrm{SO}_{2} \text { Conc } \\
\text { Allowed }\end{array}$ & ppmvd & 500 & 500 & 500 & 500 & 500 \\
\hline $\mathrm{SO}_{2} \mathrm{lb} / \mathrm{hr}$ & $\mathrm{Lb} / \mathrm{hr}$ & 15.15 & 14.54 & 12.82 & 33.95 & 32.38 \\
\hline $\begin{array}{l}\mathrm{SO}_{2} \mathrm{lb} / \mathrm{ton} \\
\text { clinker }\end{array}$ & Lb/ton & 0.203 & 0.207 & 0.174 & 0.462 & 0.441 \\
\hline
\end{tabular}

Table 9 Summary of NOX and SOX emissions.

The results presented in Table 9 are important for the support of one the main hypotheses of the study - that carpet does not significantly effect the NOX emissions for the kiln, despite having a higher nitrogen content due to the nylon in the carpet. First, for both coal and carpet co-fire the emissions are significantly below the limits allowed for both NOX and SOX. Second, the nitrous oxide emissions are not significantly different for carpet relative to coal. Third, the SOX emissions for carpet do appear higher than those for coal. This was thought to have occurred because the temperature profile in the kiln was not optimized for carpet and led to too hot conditions at the flame end, and hence a shift in the equilibrium of the oxidation of the sulfur in the feed towards $\mathrm{SO}_{2}$ and away from the solid $\mathrm{SO}_{3}{ }^{-}$components. However, there was significant variability in the $\mathrm{SO}_{2}$ results from run to run, for example during some calibration and testing runs prior to the $5^{\text {th }}$ of November, the ppm by volume of $\mathrm{SO}_{2}$ was as high as 2129 and as low as 39, this variability is not due to the instrumentation but the kiln conditions, which take a long time to stabilize and which can be strongly affected by the exact oxidizing conditions.

The other emission components were halogens, metals and dioxins/furans. There were no major differences between the carpet co-fire and the coal only cases.

Overall this data is supportive of the $5^{\text {th }}$ hypothesis with which the trial was started. The emissions from burning carpet would not be any worse that those from coal. The trial was to gather data on emissions necessary for pursuit of a permit from the Pennsylvania EPD. Nitrous oxide emissions were of specific concern due to the nitrogen content of the nylon in the carpet fiber. 


\section{Supply Chain Technical Assessment}

There are several important subcomponents of the supply chain that require discussion. A short section on each of the important ones is included.

\section{A. Collection}

Collection capacity was not tested as part of the trial. The collector had the capability of storing significant amounts of carpet for the trial and hence could stockpile the carpet ahead of the required volumes. This does reveal a particular problem with high volume applications, such as fuel for cement kilns. The collection capacity is hard to ramp up and down quickly, hence it must be known that the demand is going to persist for some time. Clearly for a trial, where a finite volume of carpet, rather than a finite rate of carpet, is to be consumed there is no point in building a collection capacity above that which already exists, but rather to opportunistically divert materials to storage when other outlets are not demanding the carpet being collected, and to get material from other sources that might not have suitable outlets.

\section{B. Handling}

The material handling of the carpet was a major problem throughout the trial. There are several points in the supply chain where the carpet must be handled and there are risks associated with them as well as costs.

The key risk in the process is the contamination of the carpet with large metal objects that can then be fed into the size reduction equipment and as a result cause major damage to the equipment. The first point of entry for foreign objects is in the collection process, where tools used to remove the carpet from the location may be inadvertedly bundled into the carpet. The second point of entry is the handling of carpet prior to feeding to the size reduction machine. For instance, if the carpet is in storage where metal objects may be on the floor then as the carpet is picked up and fed to the machine objects can be picked up as well. Similarly, if the shredded material goes back onto the floor and is swept into a walking floor truck, then the same source of contamination can cause problems at feeding point for the kiln.

This leads to a couple of recommendations for the material handling. First, the material should be kept off floors and moved by using conveyors rather than by forklifts. The conveyors should move the material from a bale breaking point to the size reduction equipment and similarly conveyors should move the material away from the size reduction equipment. The material should be put through a metal detection system before entering the size reduction equipment. The detection should not attempt to remove the material but should stop the conveyor to allow a visual inspection of the carpet. It is probably necessary to have a portable metal detector that can then be scanned along the belt in front of the machine to isolate the exact position. A second alternative would be to have a system where the carpet is unrolled and lifted by a hoist system so that any entrained objects will fall out. The issue with this system is the added cost of the hoisting mechanism and the issue of how easily the carpet will unroll. This type of system is probably better suited to when the carpet must be sorted when the hoist system can be directed down different paths for different carpet types as in the automated system that was developed in Europe.

Overall the most important aspect of material handling is to minimize the number of times that the carpet must be moved, particularly intermediate steps of transportation from one site to another. This suggests that the system of using an intermediate processor, such as in this trial, is not ideal. It would be better to site the size reduction equipment next to the feed point for the kiln and use the feed hopper at the kiln as intermediate storage of the size reduced carpet. The density of the shredded material is clearly low - 4-8 lbs/ft^3, and keeping enough in reserve in case of down time of the size reduction equipment is problematic. 


\section{Size reduction}

There were two major points of learning that were achieved during the first phase of the trail with respect to the size reduction equipment. The first was the arrangement and geometry of the knives on the rotating shaft. The second was in the ease of access to the rotor for maintenance and repositioning. The original machine design for carpet size reduction was based on the idea that we needed to have a large number of "teeth" with a small bite to tear small chunks of carpet out of the flat pieces. However, the first phase of the trial demonstrated that this was relatively ineffective because of the way that the carpet entered the cutting zone. The major problem with low throughputs was not caused by an inability to cut the carpet, but by the relatively long period the machine spent trying to "grab" the next piece of carpet into the zone. This was exacerbated by the random orientation of the carpet rolls to the axis of the shaft. If the roll presented itself "end on" then it was hard for the system to grab the roll. If it presented itself "edge on" then it would rapidly unroll and feed to the system.

This suggested two important improvements that could be made to the system. First, the material handling system could do a better job of orienting the carpet rolls to the axis of the shaft. This could be achieved by a limited amount of funneling of the carpet into the side of the hopper at right angles to the machine. Second, the aggressiveness of the bite of the knives on the rollers could be increased. This second option was pursued in the redesigned machine, and a much more consistent rate of carpet reaching the cutting plane was achieved.

The second issue was the downtime required for maintaining the machine. It is an inevitable fact that size reduction of carpet will require frequent maintenance of the machine to keep the tolerance on the gap between the rotating cutters and the stationary fixed bed knife within specification. This is due to the relatively aggressive wear of the carpet on the cutting surface as a result of the calcium carbonate filler used. Clearly the goal should be to keep the wear to a minimum, but there will be the need to rotate and replace the knives and move the counterknife forward on a regular basis. The second cause of maintenance is the unanticipated replacement that might be caused by foreign objects breaking a knife. Therefore the second improvement to the original machine was to enable much better access to the rotor for maintenance.

Another issue that has been of concern in the size reduction process is the generation of dust that can be both a health and possibly a combustion hazard. In the trial we did not find that the dust generation was excessive - the dust did not get released from the cutting process into the air space above the machine. The largest source of suspended particulates came on the other side of the rotor as the material exited the system and fell onto the floor. Clearly this could be minimized by reducing the drop from the cutting zone to the material removal zone.

\section{Dust Generation}

Post consumer carpet contains a reasonable amount of "dirt" which, along with the calcium carbonate in the backing, can be liberated during the size reduction process. The liberation of the material is related to how much damage is done to the carpet through the size reduction. In our case we do not want to have too much disruption of the carpet, but want to merely cut into small pieces. There are several ways to avoid the generation of dust.

1) Mist water on to the rotor to knock the dust out of the atmosphere. This was the solution adopted in the first generation of the machine because the water also helped with cooling.

2) Enclose the size reduction system and use positive air flow (negative pressure) to suck the dust into a bag house dust handling system.

3) Avoid generating the dust through the process by minimizing the disruption of the carpet backing. This turned out to be the solution that was achieved by the second generation equipment. 
Another way that dust could be generated is through the material handling after size reduction itself. The carpet pieces should be moved by conveyor rather than being physically moved by pushing along the floor of the building, which can generate dust, and also the distance between the conveyor and the machine exit should be reasonably small to avoid "dropping" the material.

\section{Heat Generation}

There are significant problems with heat generation from the size reduction process. The heat is generated by the friction of the carpet in the tearing or cutting process. The heat often builds up on the rotor making it extremely hot. If there are materials that are capable of melting at the rotor temperature then they will soften and start to glue the carpet together, thus increasing the amount of effort required to separate the material and through a positive feedback, increase the temperature of the rotor still further. Eventually this can lead to the ignition of the material inside the size reduction equipment and a dangerous fire hazard. There are several ways in which this problem was mitigated in our size reduction equipment.

1) The rotor was internally cooled with water. This is an active means of removing heat from the rotor and is limited by the distribution of the water through the rotor.

2) The cutting of the carpet rather than tearing the carpet. The mechanism of size reduction used in our equipment creates very little heat in the first place because it creates very little friction during the cutting process.

3) Spraying water onto the carpet/rotor to externally cool the rotor. The spray removes heat, directly from the rotor surface and carpet, but runs the risk of creating agglomerates of carpet by wetting it. Also if the material is to be immediately used in the kiln, then it also reduces its heat of combustion due to the water. This mechanism was adopted in the first generation of the machine, because heat build up on the rotor was a problem. The redesigned equipment avoided this problem both through internal cooling and the improved cutting action.

\section{Size Reduction System Conclusion}

In conclusion, we were unable to devise an effective feed system to the size reduction equipment in two ways. First, we had a highly inefficient handling system for the bales, using a forklift truck. This was not a problem when the machine was not processing carpet effectively, but in the second phase of the trial the feeding and removal of material from the machine became a bottleneck. Second, we did not have an effective way to screen for metal in the incoming material. This proved very damaging because in the second trial run a piece of metal was entrained into the machine from the floor of the building. This metal caused the gearbox to fail and a further delay in the trial that eventually proved fatal to the chances of continuing. Both of these problems could be solved in a full scale system, with the installation of conveyors to handle the material and the use of a metal detector. There are also other drive systems, such as hydraulic or magnetically coupled systems that would not have the same issues with the gearbox drive and therefore might be more robust for this application. These drive systems are sold by other manufacturers, such as Granutech and Vecoplan. The magnetically coupled system was unavailable at the time of the trial and the other system was significantly more expensive and therefore outside of the cost parameters for the trial.

\section{Feeding}

One of the major problems encountered during the trial was the feeding of the carpet to the cement kiln. The system being used had been designed for wood chips and not for carpet. This led to significant problems with the "bridging" of the material in the feed hopper and a lack of consistent flow to the firing point. The reason for this was that the converging design of the feed from the hopper to the rotary air valve caused the material to jam. The preparation of the feed material 
played a critical role in this. If the size reduction machine was out of tolerance, then the material would not be completely separated but would look like trapezoidal flags connected along a string. These long pieces would cause the system particular problems. If the material was size reduced twice, this would create a much finer material that would not have the problems of the stringy material. However, it would still have the ability to compact in the hopper and cause bridging.

This proved to be a significant problem. The pictures and descriptions in Appendix A show the impact of the inability to avoid the compression of the carpet scraps in the feed system. This led to two operational problems. First, the system had to have constant attention from the operators, which was a very significant drain on their resources and willingness to participate in the trial. Second, there was always the fear that the system would jam and immediately cause a drop in the carpet feed to the kiln. This operational uncertainty meant that the kiln might have to cut back on feed rate of material to avoid off-spec product. The economic risk associated with this was ultimately the cause for the end of the trial.

There were several solutions that were suggested to this problem. The most straightforward would be to redesign the feed system to avoid the converging flow from the hopper and to include a short screw conveyor to keep the material from bridging. The main problem is that the screw conveyor itself can jam if the stringy material is not kept to a minimum. The second is to make sure the material is properly size reduced to avoid the strings. Problems in the feed system are clearly extremely detrimental to the smooth operation of the kiln, as they will vary the fuel load being delivered by the alternative fuel system. Ultimately it was the failure in this part of the system that was the most critical factor to the termination of the trial. Once the material entered the rotary airlock there were no problems encountered in the air conveying of the carpet to the kiln. Therefore this part of the feed system still seems the most feasible way to get relatively high volumes of carpet into the kiln.

\section{E. Burning}

The carpet was fed to the kiln at approximately 2-2.5 tons/hr and there were no problems experienced in the complete combustion of the carpet at these rates. The carpet did bun extremely well, in fact the only problem encountered was that it burnt too well and too intensely at the burner end of the kiln. The skin temperature of the kiln did experience significant excursions, essentially it became hot enough for the kiln operators to be concerned with it exceeding the safe operating parameters. This was of particular concern because the kiln brick lining had been compromised by "throwing a brick" several weeks before the trial started, and hence there was even greater caution about the temperatures inside the kiln at that time.

The solution to the overly rapid combustion in the kiln was thought to be to mix the carpet with wood chips in the feed system. This mixing would have several beneficial effects. First, it was thought that the carpet/wood chip blend would feed more consistently and avoid the bridging problems associated with the pure carpet. Second, the presence of the wood chips would raise the burnout time of the fuel and hence lower the intensity of the heat input into the burner end of the kiln. This would allow a higher feed rate of the mixture and ultimately of the carpet as well as raising the value of the wood chips as a fuel to the kiln. The termination of the trial prevented us from trying this particular option but it is a recommendation that such a strategy be tried in the future. 


\section{Supply Chain Economic Assessment}

\section{A. Overall Business Case - Base Case}

The base case business case for the kiln was based on the displacement of coal fuel by carpet. The kiln pays a certain fixed long term price for its coal, which it then has to size reduce to feed the kiln. The coal size reduction system is extremely efficient and high volume. Therefore the raw cost of the coal fed to the kiln is not significantly different from its long-term purchase cost. The base level assumptions for various costs are given in Table 10. The various costs of the carpet supply chain components are given in Table 11.

\begin{tabular}{|l|l|}
\hline Cost Category & Base Case Value \\
\hline Electricity & $\$ 0.07 / \mathrm{kWh}$ \\
\hline Direct Labor & $\$ 10 / \mathrm{hr}$ \\
\hline Ovhd Rate on Labor & $30 \%$ \\
\hline Hours per year & 6000 \\
\hline Uptime Percentage & $90 \%$ \\
\hline Nominal Throughput & $7000 \mathrm{lbs} / \mathrm{hr}$ \\
\hline
\end{tabular}

Table 10 Base Case Economic Assumption Values

\begin{tabular}{|l|l|l|l|}
\hline $\begin{array}{l}\text { Supply Chain } \\
\text { Component }\end{array}$ & $\begin{array}{l}\text { Cost } \\
\text { c/lb }\end{array}$ & $\begin{array}{l}\text { Original cost } \\
\text { estimate }\end{array}$ & Final Cost Data Source \\
\hline $\begin{array}{l}\text { Initial Baling and } \\
\text { Loading }\end{array}$ & 1.5 & $\begin{array}{l}\text { Built into } \\
\text { disposal } \\
\text { avoidance value. }\end{array}$ & $\begin{array}{l}\text { Carpetcycle llc, observed cost reported as } \\
\text { part of trial (This would be expected to } \\
\text { come down with high volume, on-going } \\
\text { operations). }\end{array}$ \\
\hline Transportation & 1.3 & 0.3 & $\begin{array}{l}\text { Carpetcycle llc, observed cost based on } \\
\text { \$550 fee for transportation from } \\
\text { Carpetcycle to Evansville }\end{array}$ \\
\hline Size Reduction & 1.5 & 0.5 & $\begin{array}{l}\text { Republic Machine calculated cost based on } \\
\text { initial trial runs and machine redesign }\end{array}$ \\
\hline Total Cost & 4.3 & 0.8 & $\begin{array}{l}\text { Trial conditions are a major cause of this } \\
\text { discrepancy, but would still not eliminate } \\
\text { all the excess cost. }\end{array}$ \\
\hline
\end{tabular}

Table 11 Overall Supply Operating Costs

This gives a certain economic margin based on the value of the btu's in the carpet which must cover the cost to process the carpet. Our initial calculations on the value of carpet did not give us a significant margin on the carpet fuel. Coal costs were assumed to be about $\$ 1.60$ per mmbtu. This means that carpet on a per lb basis is worth approximately $1.2 \mathrm{c} / \mathrm{lb}$ based on $7500 \mathrm{btu} / \mathrm{lb}$ fuel value. We had initially assumed that the carpet would burn at approximately 10,000 btu/lb and this additional loss of value was significant. However, the biggest shock was the cost of transportation. The first pass economics had assumed a cost of $\$ 1.5$ a load mile, which leads to a cost of $0.3 \mathrm{c} / \mathrm{lb}$ based on a full load. The actual cost of transportation was $\$ 5.50 /$ load mile, based on the 100 mile distance and the $\$ 550 /$ load as the actual paid freight cost. This is higher by a factor of 3.7 and immediately wipes out the value of the carpet, at 1.3c/lb.

The operating costs are not the only component of the overall economics. There are also some significant capital costs associated with the equipment. The majority of the new capital equipment that would be required is at the cement kiln in order to store the material and feed it to the kiln. We do not have good estimates of this, because there are many ways in which this could be 
implemented depending on the complexity and variety of fuels that would end up being used. A second investment is in the materials handling and size reduction equipment.

\section{B. Other Economic Scenarios}

There is significant uncertainty surrounding the economic data, and it will also vary by region for the transportation and for the cost of landfill disposal. Therefore it is worth exploring the economic scenarios more closely to determine whether there is a set of conditions under which carpet might make a case for being economic as a fuel. It is also important to consider whether the overall system economic picture is as bleak for each of the components.

The transportation cost was in 2004-5 and could well be higher today for the same route. This shows the dependency of the transportation cost on issues such as backhaul capability and specific journey features, as well as the short-term nature of the contract for the transportation. There may be a greater margin to be had for the fuel. Recent data from an industrial partner in the carpet industry indicates they pay approximately $\$ 3.50 / \mathrm{mmbtu}$ for coal that has already been prepared to be burned. This is the equivalent to the carpet after shredding, and is again significantly higher than the initial assumption. Table 12 shows the best and worst cases for the overall economics. This shows that with the current cost structure there is a huge deficit between the economic value and the overall cost. It is also clear that the cost of coal would have to rise significantly for this to work. It is certainly the case that the transportation and baling costs could be significantly lower than in the trial because of the ability to scale up the initial collection infrastructure and the regular contract that could be established for supplying the kiln. The problem of the size reduction would still remain, the cost is very close to the value of the carpet as a fuel, it may be more or less depending on the exact btu content of the carpet and the cost of coal. The major cost components of the size reduction system are listed in Table 13.

\begin{tabular}{|l|l|l|l|l|}
\hline Cost or Value Category & Units & Best Case & Average Case & Worst Case \\
\hline Avoided Landfill Tip Fee & $\$ /$ ton & $\$ 85$ & $\$ 35$ & $\$ 15$ \\
\hline Avoided Cost of Coal & $\$ /$ mmbtu & $\$ 3.50$ & $\$ 1.6$ & $\$ 1.3$ \\
\hline Transportation Cost & $\$ /$ load mile & $\$ 1.5$ & $\$ 2.00$ & $\$ 5.5$ \\
\hline Baling \& Handling Cost & $\$ /$ lb carpet & $\$ 0.02$ & $\$ 0.03$ & $\$ 0.05$ \\
\hline Size Reduction Cost & \$/lb carpet & $\$ 0.005$ & $\$ 0.015$ & $\$ 0.03$ \\
\hline Carpet Fuel Content & Btu/lb & 12000 & 9000 & 7500 \\
\hline Economic System Gain & \$/lb (loss) & 0.6 & $(0.02)$ & $(0.08)$ \\
\hline
\end{tabular}

Table 12 Best, Average and Worst Cases for Economics of Carpet as a Fuel

\begin{tabular}{|l|l|l|}
\hline Cost Category & Value (\$1000’s) & Cost/lb \\
\hline Capital Cost & 890 & \\
\hline Maintenance (Wear Parts) & 60 & 0.006 \\
\hline Labor (5 workers) & 390 & 0.004 \\
\hline Utilities (Diesel \& Electric) & 300 & 0.003 \\
\hline
\end{tabular}

Table 13 Size Reduction Cost Components Base Case.

An alternative way to consider the economics is to examine the profit made as a function of the avoided landfill fee, because this is the quantity that will vary by region. Figure 2 shows this relationship for the Average Case where only the landfill tip fee has been allowed to vary. The breakeven point is around \$70/ton. The breakeven points for the best and worse cases are (\$27.00), in other words you can pay $\$ 27.00 /$ ton to get the carpet, and $\$ 166 /$ ton. This shows the huge spread in costs caused by the uncertainty in costs and also the possible variation due to the volumes involved. 
Economic Gain per Ton of Carpet

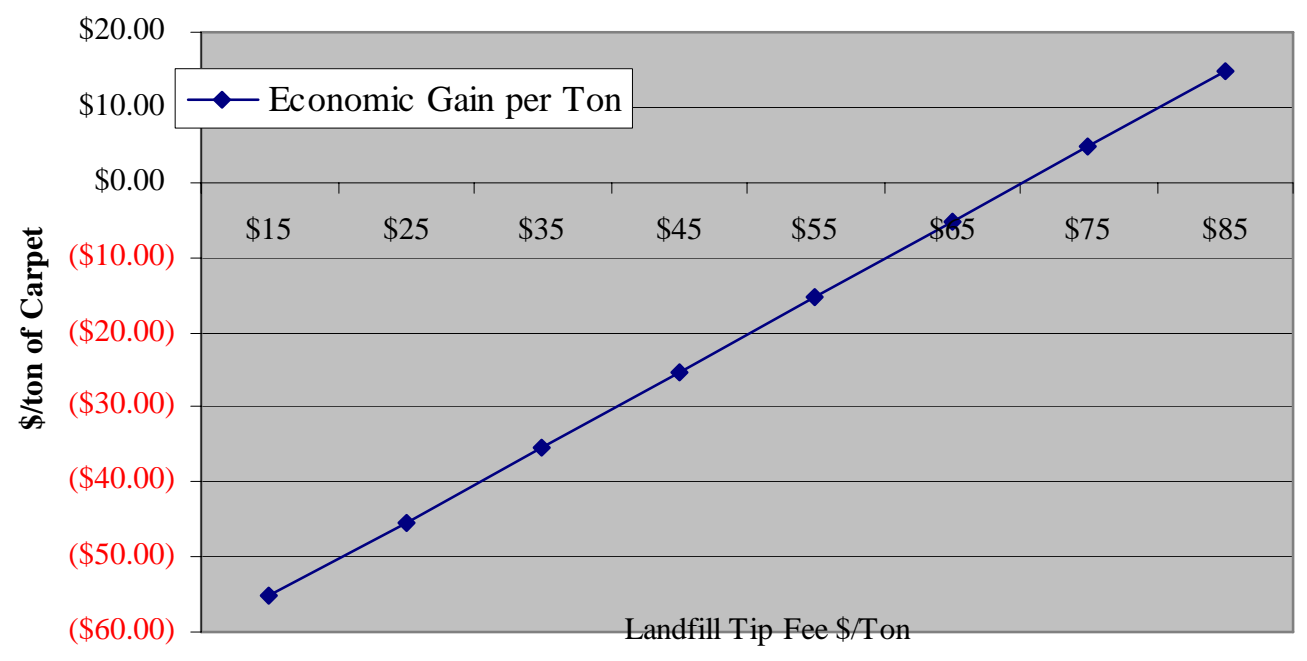

Figure 2 Overall Economics as a Function of Landfill Tip Fee for the Average Case of other costs and values.

\section{Business Cases for the Supply Chain Components}

The business case for the collector is reasonable. The collector estimated that the cost of baling the carpet was $1.5 \mathrm{c} / \mathrm{lb}$, or $\$ 30 /$ ton, which can be covered by the cost of carpet disposal as long as the collector is able to recover this from the initial site of collection. In New Jersey this is actually a problem - the waste haulers are required to do curbside pickup of carpet and hence it can be left on the street. This means that the cost of disposal of the carpet is bundled into the general waste handling fee that households pay. We do not consider this to be an insurmountable barrier to adoption in other parts of the country. In addition, there are professional removal activities for commercial buildings that can build this cost into the disposal fee. The landfill fee equivalent to the cost of the carpet transportation and preparation as a fuel is $\$ 86.00 /$ ton, this is a high number for many parts of the country but in the Northeast there are locations where the cost exceeds this. The $\$ 0.015 \mathrm{c} / \mathrm{lb}$ for baling does not include other activities associated with collecting the carpet from a dealer or a transfer station and ensuring the carpet is essentially free of large debris. These additional factors could increase the cost of the overall system by a few cents a lb. There is no business case for the intermediate processor if all the carpet is to be burnt. An intermediate processor might be feasible if sorting operations are to be performed to recover a certain fraction of the collected stream for use in other higher value outlets. The business case for the kiln is weak at the current time. The risks and costs associated with developing new sources of alternative fuels are high, and the rewards need to be in direct payoff to the kilns rather than just in avoided fuel costs. If fuel costs continue to rise, or $\mathrm{CO} 2$ emission caps are implemented with a direct fossil fuel component cap, then the case may become stronger.

\section{Business case for using carpet to prime recycling infrastructure}

The business case for using carpet as a fuel in cement kilns does not stand up to scrutiny. Its use in combination with other activities might be more effective, but this will clearly depend on the volumes required for other applications and the value of cross-subsidy. The clear advantage of 
having cement kilns is to the network and not necessarily to the kiln itself. Therefore this is also its biggest weakness - how to motivate the participation of a kiln in a network.

\section{Conclusions}

The use of carpet as a fuel in a cement kiln was demonstrated at the level of $15 \%$ of fuel, a rate of approximately 2 tons of carpet per hour in the long dry kiln at Evansville, PA owned by Lehigh Cement. We conclude that at this time of writing, the economic barriers to the adoption of carpet at this kiln are too high. The multiple material handling steps and intermediary processors make the carpet too expensive relative to coal entering the kiln. The key barriers to this could be reduced if the kiln itself were to operate the system from the point of shipment to the kiln, avoiding the additional material handling steps of the walking floor trailer, and automating a lot of the material handling from the point of receipt of the baled carpet through its storage in a feed hopper. Thus, we would conclude that the steady state operation of a carpet feed system would be feasible under these conditions, but that the economics would be relatively marginal given the capital outlay that would have to be made in order to support the operation. The key uncertainty in this equation is the cost of size reduction, because the throughput variability was high and the amount of carpet that could be fed to the kiln was restricted by a number of different factors.

A key conclusion is that the steady state operation of the fuel system is NOT the driving force for the economic analysis. In a sold-out market for portland cement the loss of operation of a single day, or even the reduction in the kiln throughput will dramatically outweigh the long term savings of the fuel. The operational risks associated with the carpet fuel were significant. First, the first generation size reduction was not effective, and would not have been able to keep up with the kiln burning rate of carpet, therefore 24/7 operation was not possible. This meant that the kiln would have to be continually rebalanced with respect to the fuel mix, which created the risk of either slower production rate or off-spec product. Second, the feed system would jam even if there was carpet available again creating the risk of a loss of fuel, and in this case one that would be hard to anticipate. Third, the carpet was extremely combustible and hence created a hotter front end of the kiln. This limited its overall rate and created the operational risk of a shutdown due to the skin temperature.

The original hypothesis was that cement kilns could be used as "primers" for high volume carpet recycling because of their ability to absorb large quantities of relatively undifferentiated carpet. The cement kiln industry has been used to an environment where energy is relatively cheap, carbon dioxide emissions unlimited and the wastes they have accepted have been hazardous or at least difficult to dispose of. These conditions are changing, and could result in an environment where waste fuels are a very desirable part of their energy supply, and not that they have to be paid to take them. The key conclusion here is that the economic environment in which the trial was conducted was a rising energy cost, but in a sold out market for the cement product. This makes the overall organization goal that of maximum throughput and not operational efficiency with respect to cost per ton. Although the calcium carbonate in the carpet will contribute to the overall cement kiln raw material it is a vanishingly small part of the overall raw material and not a significant saving to the kiln.

\section{Products Developed}

\section{Publications}

Two referee conference publications were written specifically as a result of the trial. 
Emissions from Combustion of Post-Consumer Carpet in a Cement Kiln, P. Lemieux, Hall, R., Realff, M., Bruce, K., Smith, P., Hinshaw, G. presented at the 2005 Conference on Incineration and Thermal Treatment Technologies, Galveston, TX, May 9-13, 2005.

Characterization of transient puff emissions from the burning of carpet waste charges in a rotary kiln combustor, Realff, M.J.; Lemieux, P.; Lucero, S.; Mulholland, J.; Smith, P.B. presented at IEEE-IAS/PCA 2005 Cement Technical Conference, Kansas City, Mo, May 15-20, 2005.

\section{Collaborations}

The collaboration between Lehigh cement and CarpetCycle llc resulted in one of the Lehigh engineers associated with the project joining CarpetCycle as part of a family relocation to continue working on carpet recycling.

\section{Technologies/Techniques}

\section{Size Reduction Machine Design}

A major success of the trial was the development of a second generation machine for the size reduction of carpet that had significantly improved the reliability and performance of the size reduction system. The technological improvements included a more refined machine for easier maintenance, and a different rotor configuration that enables the throughput of the system to be more steady. The size reduction system is described in more detail in Appendix ??

A more subtle and indirect effect is that other shredder distributors and manufacturers, such as Vecoplan and Granutech, have also become more engaged with the carpet recycling industry and improved their offerings. This cannot be contributed to the trial activities alone, but the focus on large volume size reduction as a task is certainly helpful in the overall development of the industry.

\section{Recommendations}

There are many things that have been learnt from the trial in each of the phases of the supply chain and for the overall system.

\section{Carpet Collection}

The carpet collection system functioned very well for the trial and there have been significant innovations in the handling of carpet. A key innovation that is starting to happen is the adoption of handling systems that allow rapid identification of the carpet whilst simultaneously unrolling the pieces to enable loose detritus from the carpet removal to be kept out of the system. This will keep larger metal objects out of the system and many of the tack strips, razor blades etc as well. It will increase throughput, especially when coupled with a horizontal baler. It is recommended that for the higher throughputs necessary to support carpet as a fuel that such systems be adopted. This recommendation is based both on the ability to significantly lower cost, but also to increase the quality of the stream. This quality comes both from the removal of items that can cause damage to downstream equipment, and the ability to sort out higher value carpet material that can be used to "subsidize" the entire system economics.

\section{Carpet Transportation}

A major cost in the trial was the transportation of carpet from the collection point to the cement kiln. It is not clear that the high cost would continue to persist if this were a regular transportation contract schedule as opposed to one off loads to be delivered. There are no specific recommendations to be made here, beyond due diligence in contract negotiations. 


\section{Carpet Handling \& Size Reduction}

The major recommendation is to install conveyors and metal detection prior to the carpet shredder and conveyors after the shredder to more effectively move the material through the system. A significant labor cost was incurred in this component of the system. It was difficult to maintain effective throughput of material and avoid equipment damage.

\section{Carpet Feeding \& Combustion}

It is recommended to try carpet mixed with wood chips as a compromise fuel. It is hypothesized that this would both improve the feed handling of the material by making it more dense and less compressible and that it would lower the btu release rate in the front part of the kiln and hence allow an overall higher feed rate of the mixed fuel. 


\section{Appendix A \\ Dave Zwicky \& Sons System Set Up}




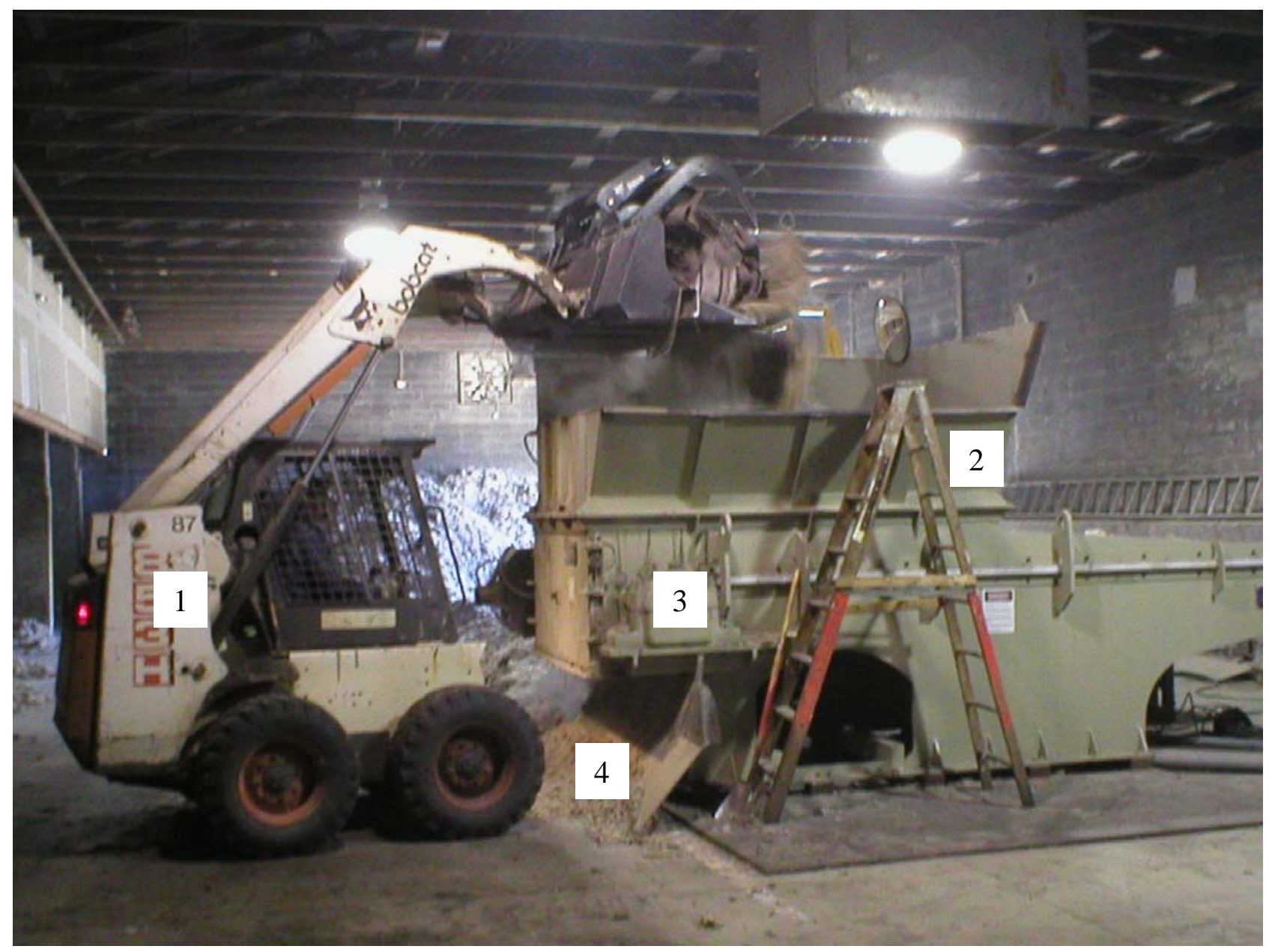

1. The bobcat is used to pick up the loose carpet and place it in the size reduction machine

2. The machine has a ram that moves the carpet forward into the cutting area

3. The rotor grabs the carpet and cuts it up

4. In the trial the carpet falls directly onto the floor of the warehouse. 


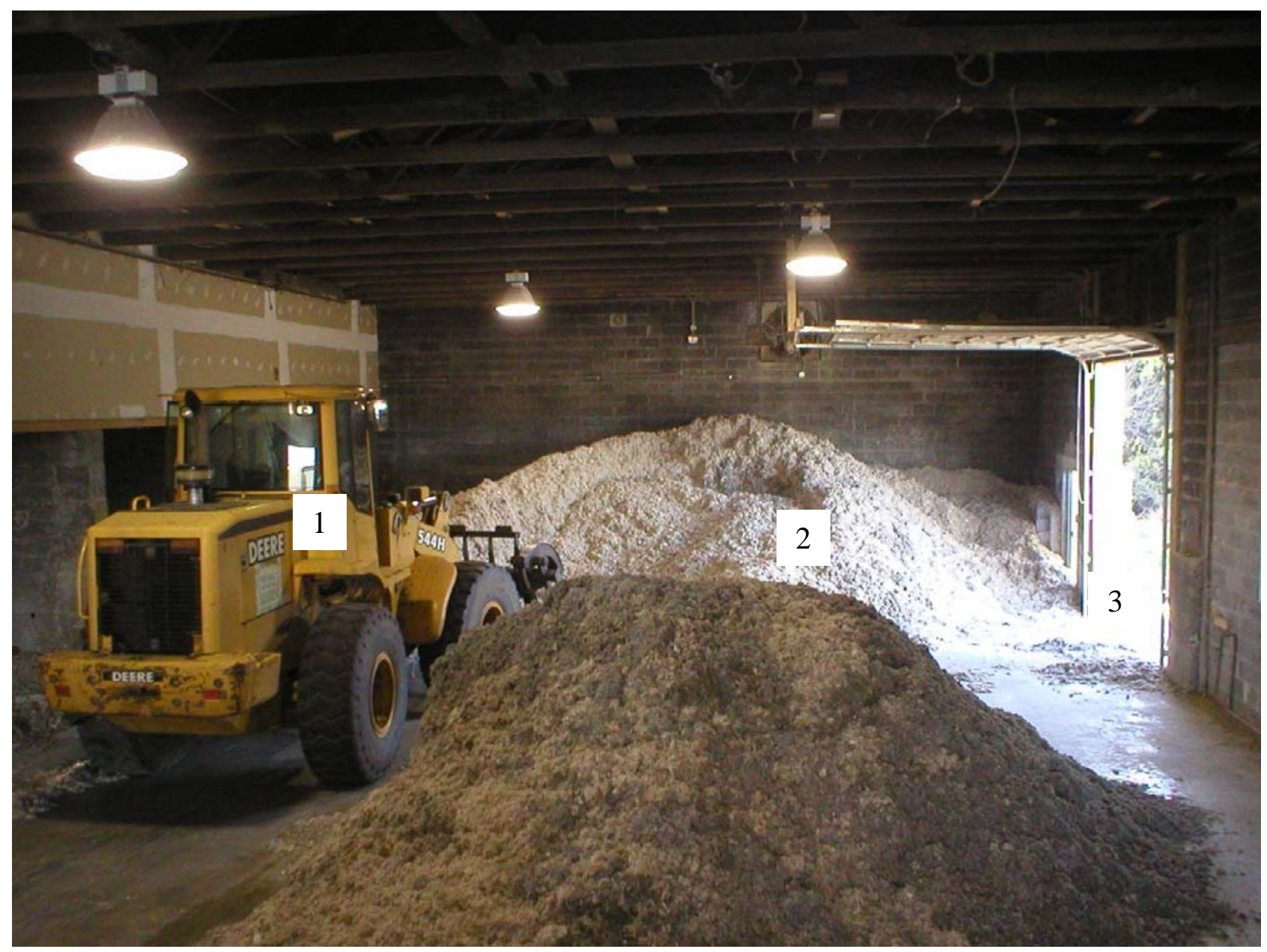

1. The processed carpet is swept from the exit of the machine into piles at the other end of the building using a cat

2. The processed carpet is piled up

3. The walking floor trailers are pulled up to the dock and the material pushed into them. 


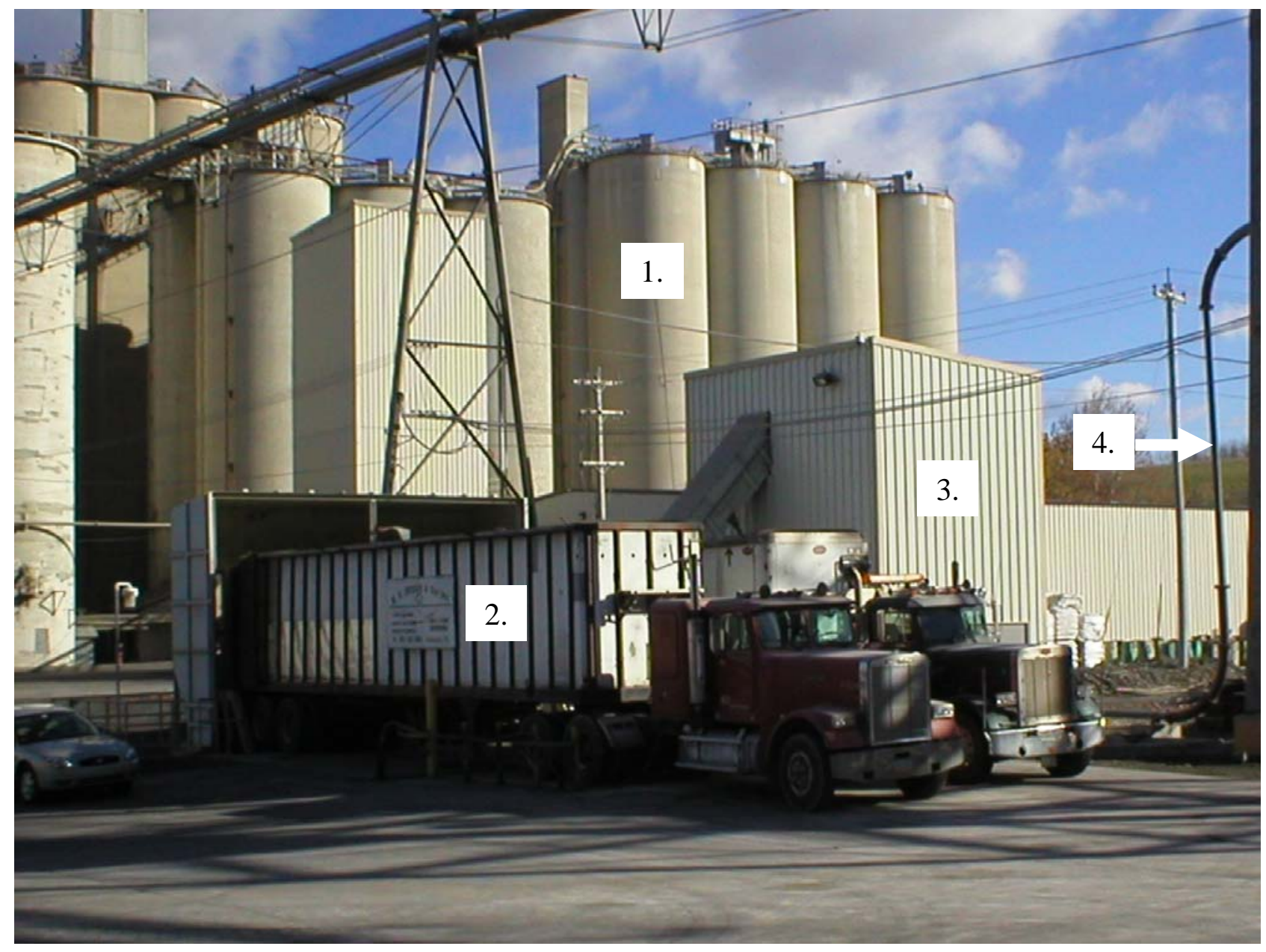

1. The raw material silos are in the background of the photo.

2. The walking floor trailers from Zwikcy are backed up to deliver the loads of shredded carpet to the storage system.

3. This building houses the weight-metered feed system and the rotary feed valve.

4. The feed line going over to the \#1 Kiln.

5. Feed Hopper into which the shredded carpet is moved from the trailer and which is the subject of the next series of photographs. 


\section{Appendix B \\ Lehigh Feed System Jam}




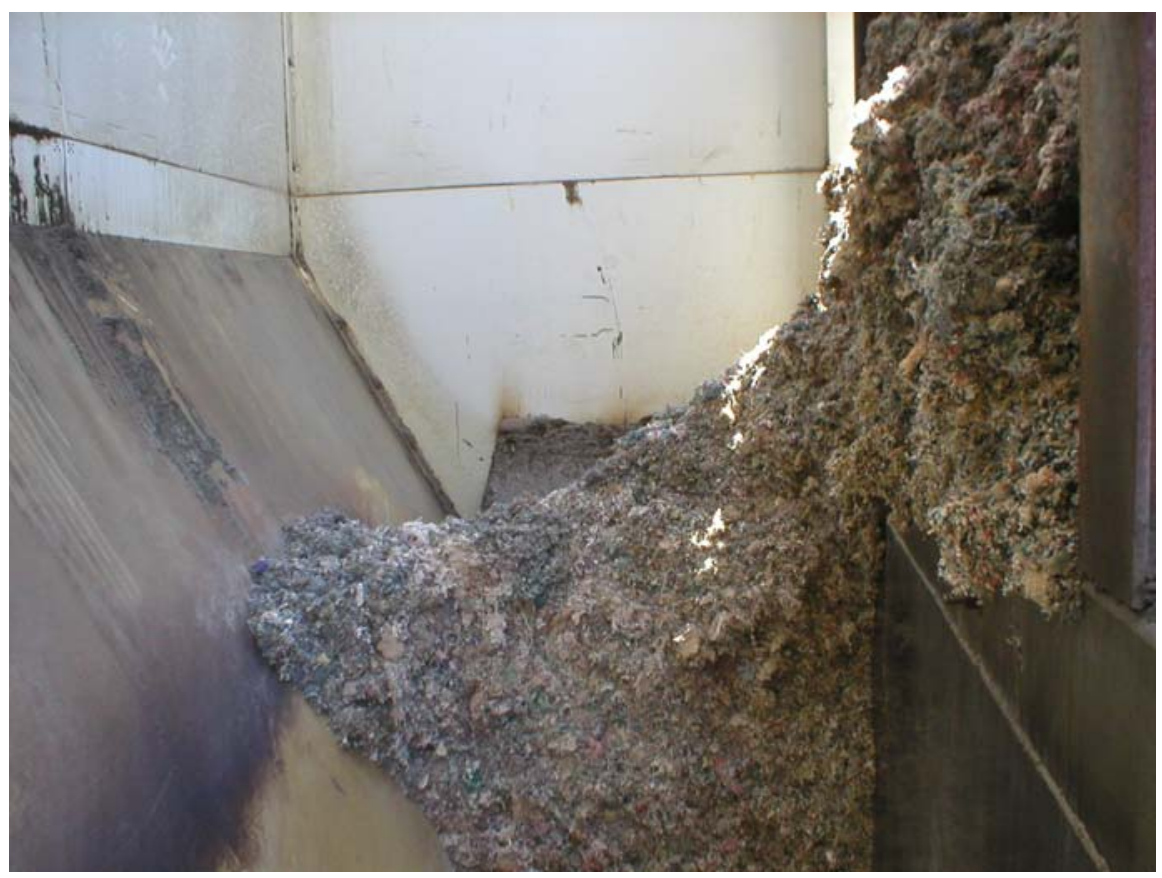

The material is delivered out of the back of the walking floor trailer into a hopper with a converging side wall to the left of the picture. This causes the mateial to be funneled into the system depicted below. The material has "jammed" solid inside the feed system and does not fall out when the inspection panel is removed.

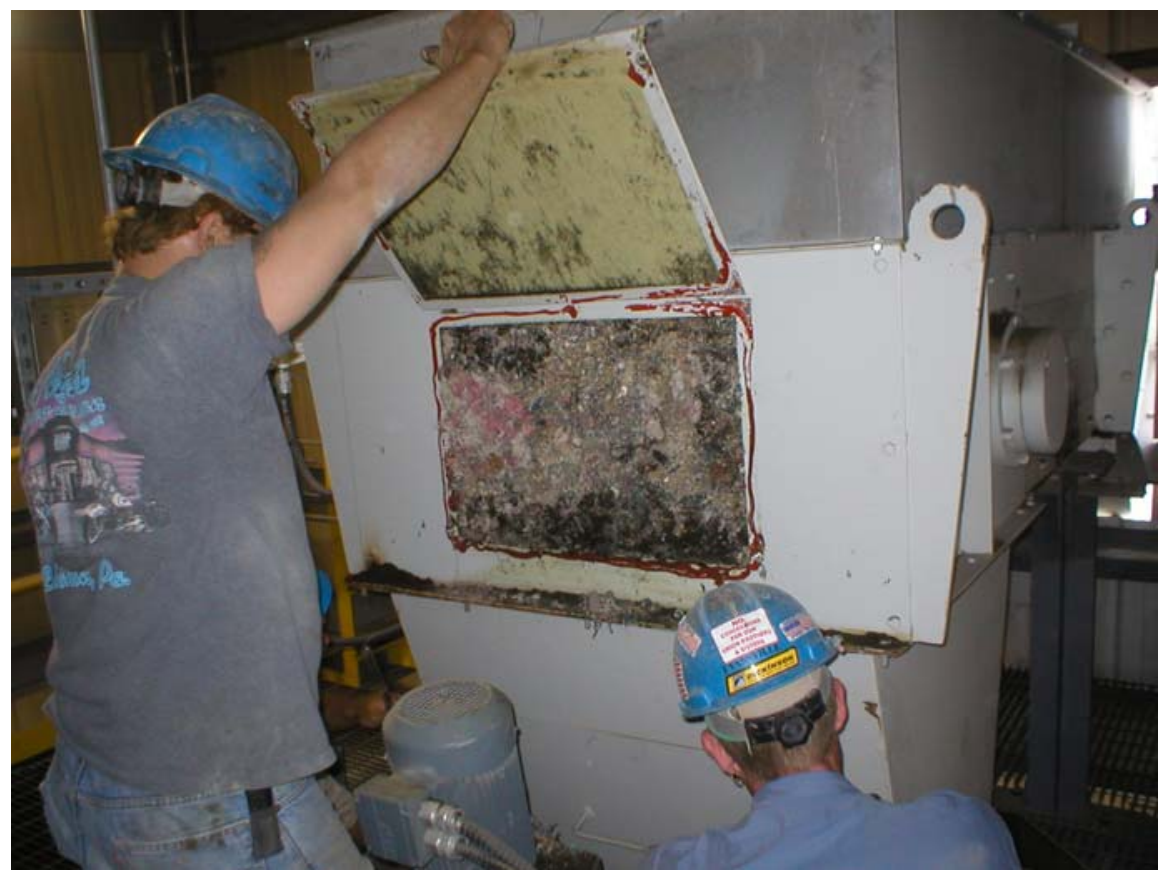




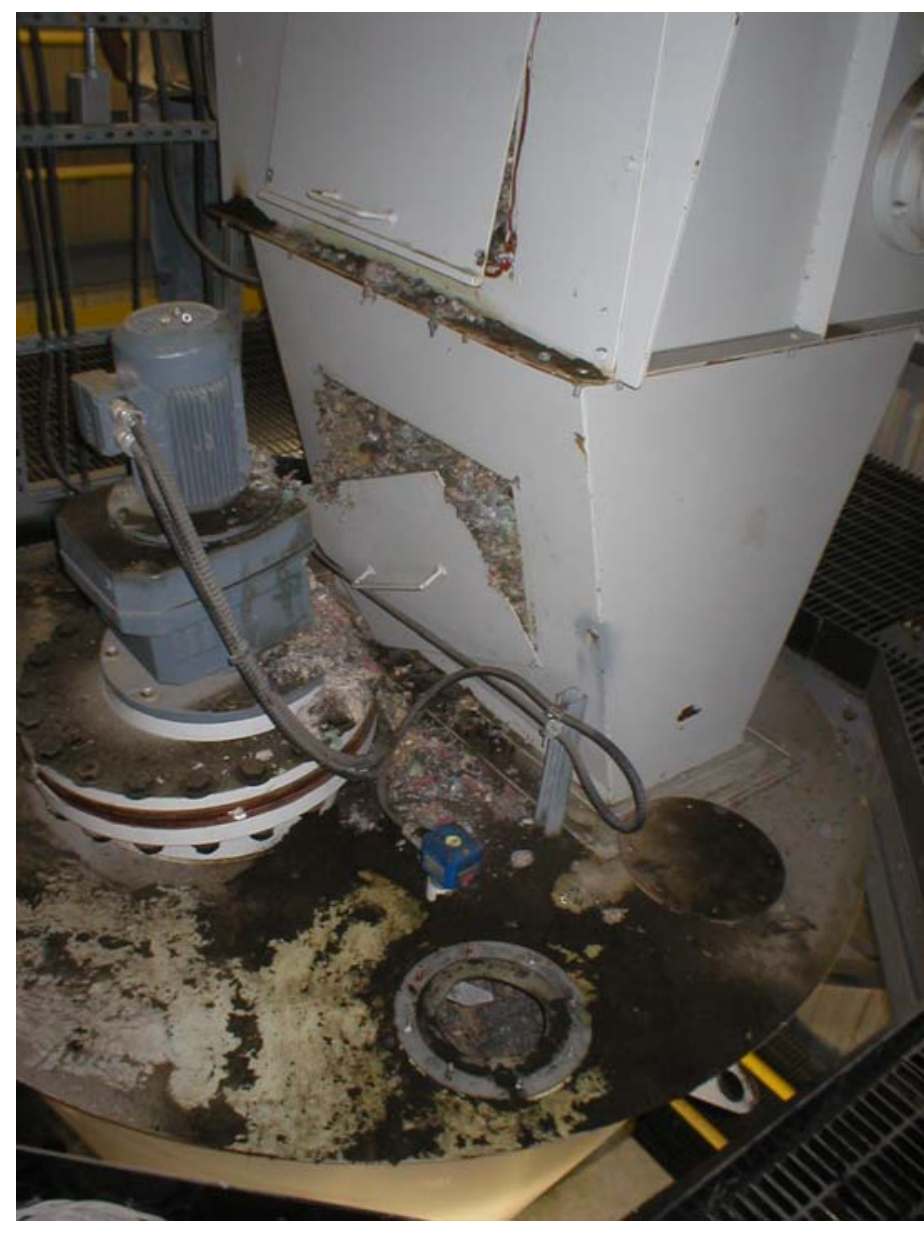

This is another view of the jammed feed system the panel that was open in the previous picture has been allowed to close and the panel below opened where it can still be seen to be jammed. Note the system continues to be converging into the valve below. An inspection panel on the valve is shown in the middle foreground. The motor shown in the left middle of the picture is for the rotary air valve

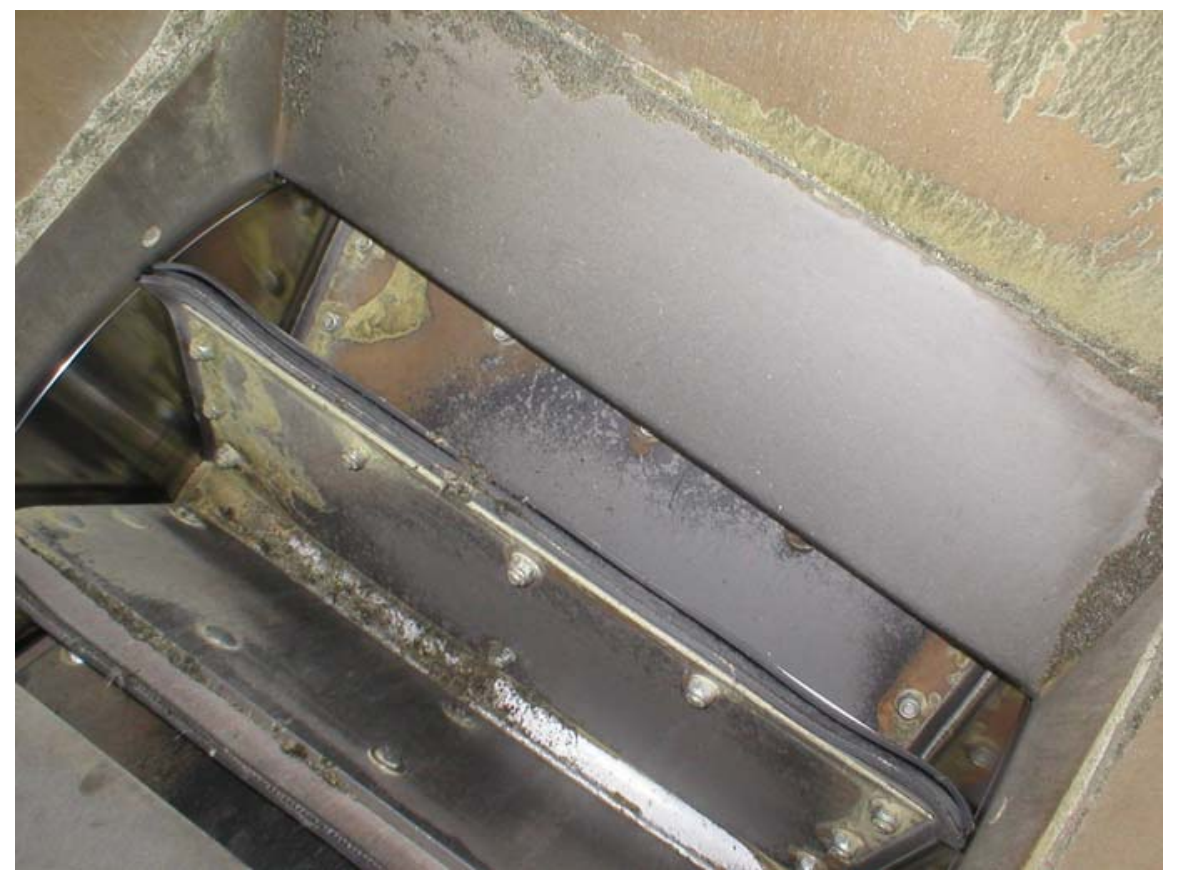

This is the rotary air lock valve. It can be seen to be totally clear, indicating that the jam has occurred in the feed system above the valve. 


\section{Appendix C \\ Details of Size Reduction System Design}




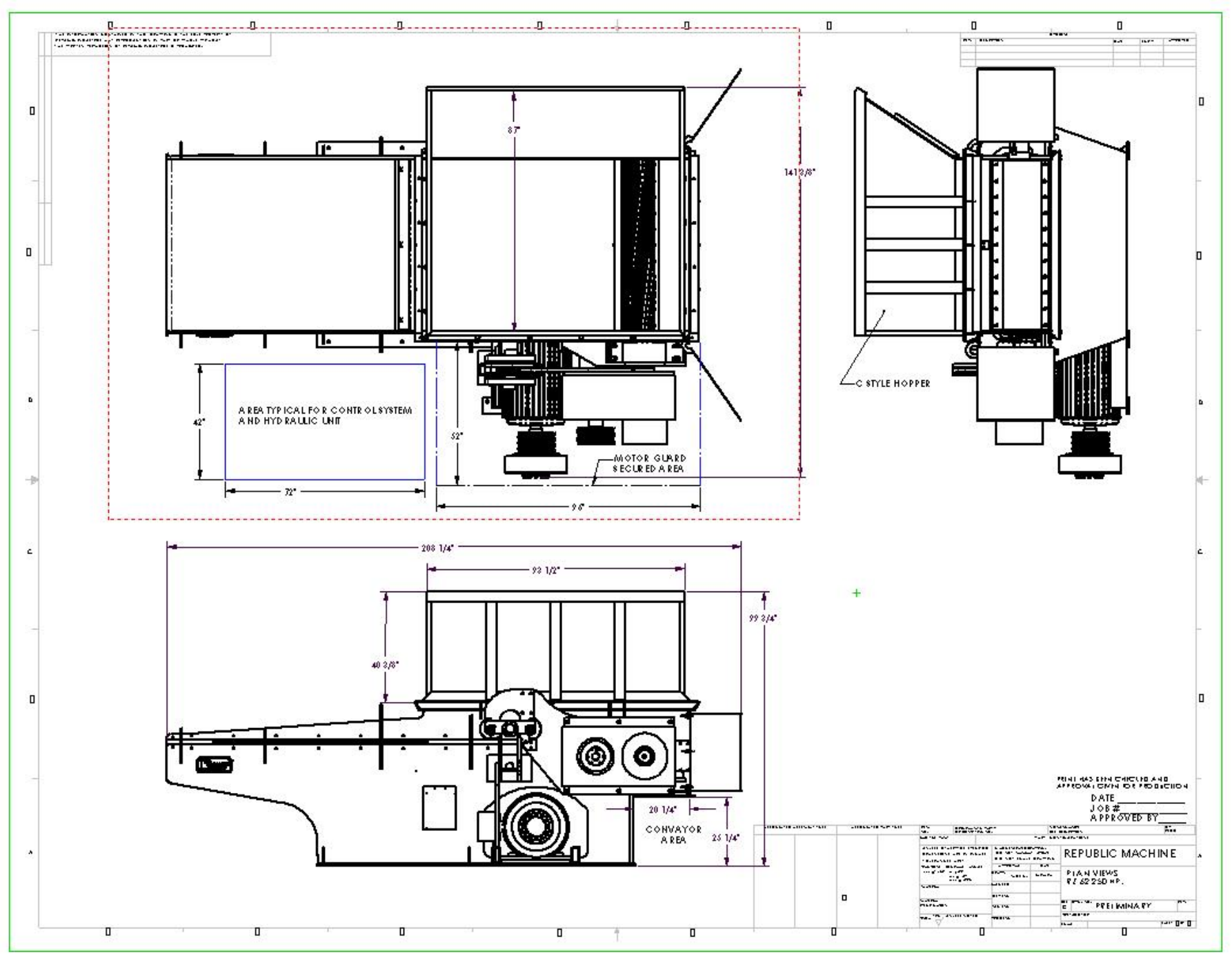

Plan View of Size Reduction Machine

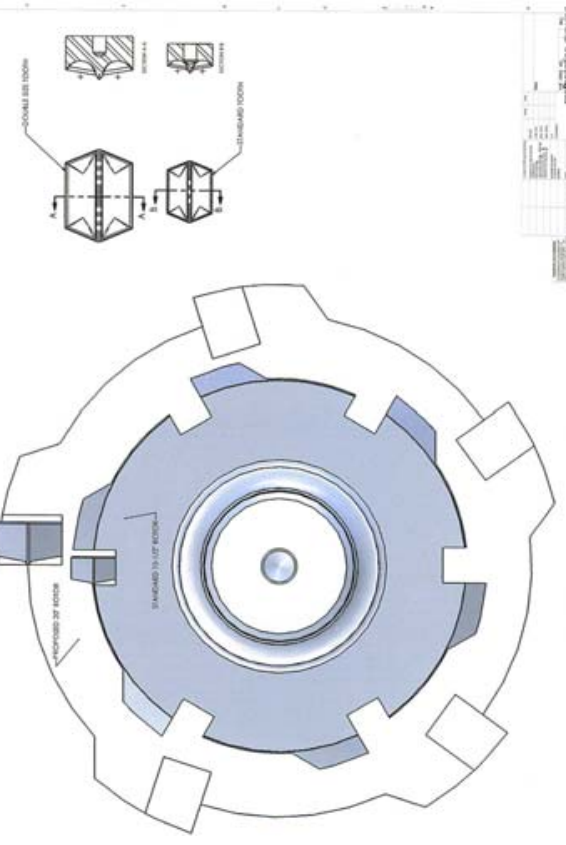

Changes in rotor design from the first to second generation machine. The rotor diameter was reduced and the teeth made larger.

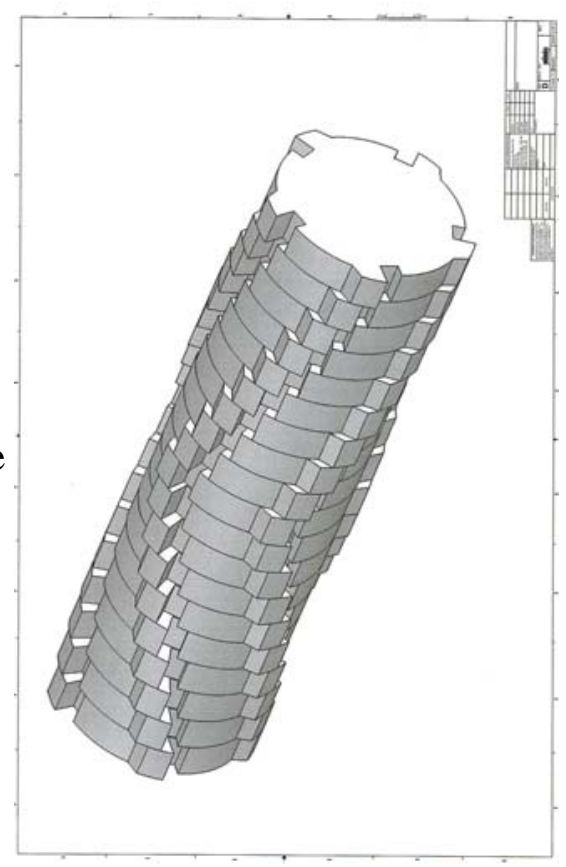




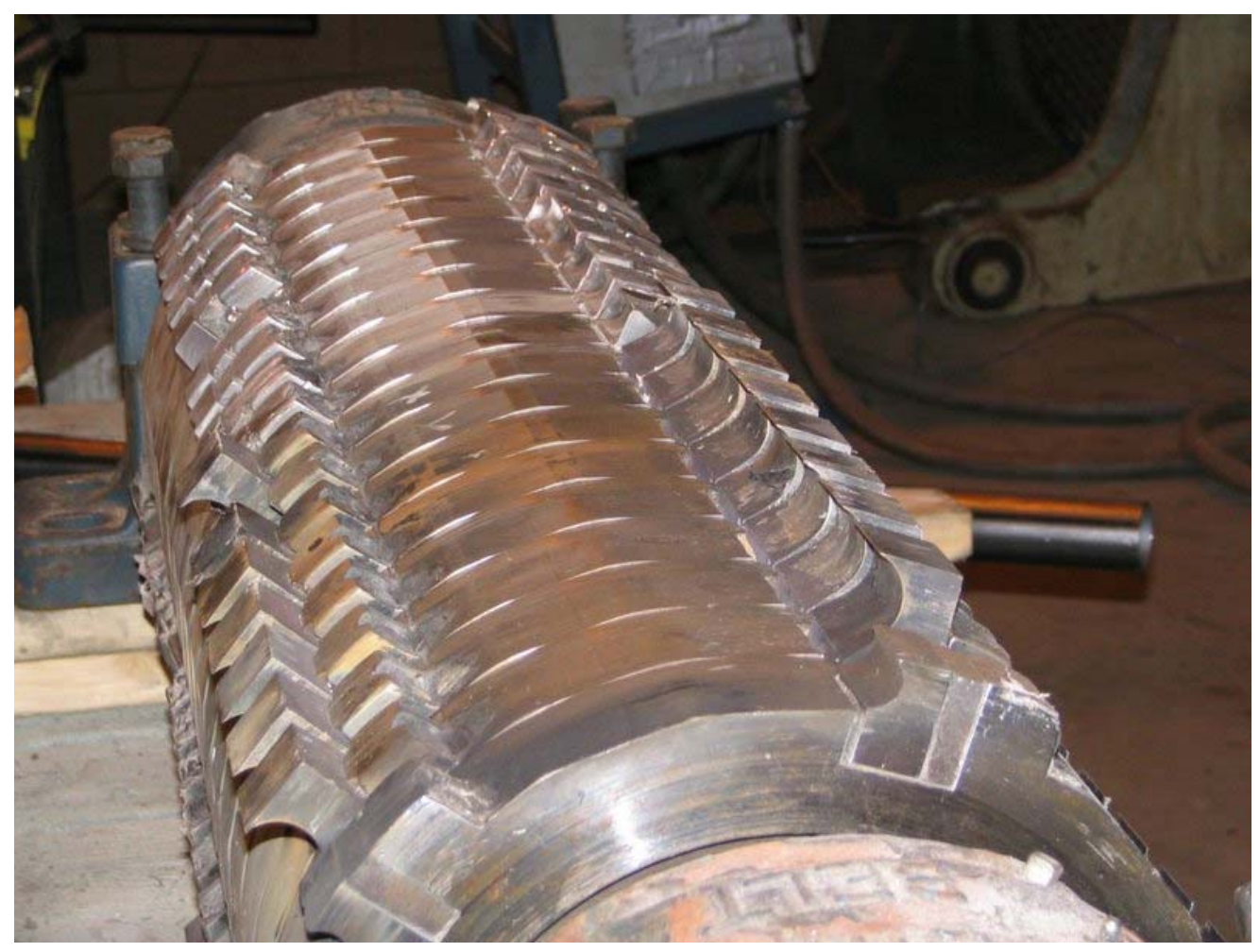

This is a picture of the new rotor, end on. The larger teeth are mounted in the sockets and stand further out from the rotor than the original design.

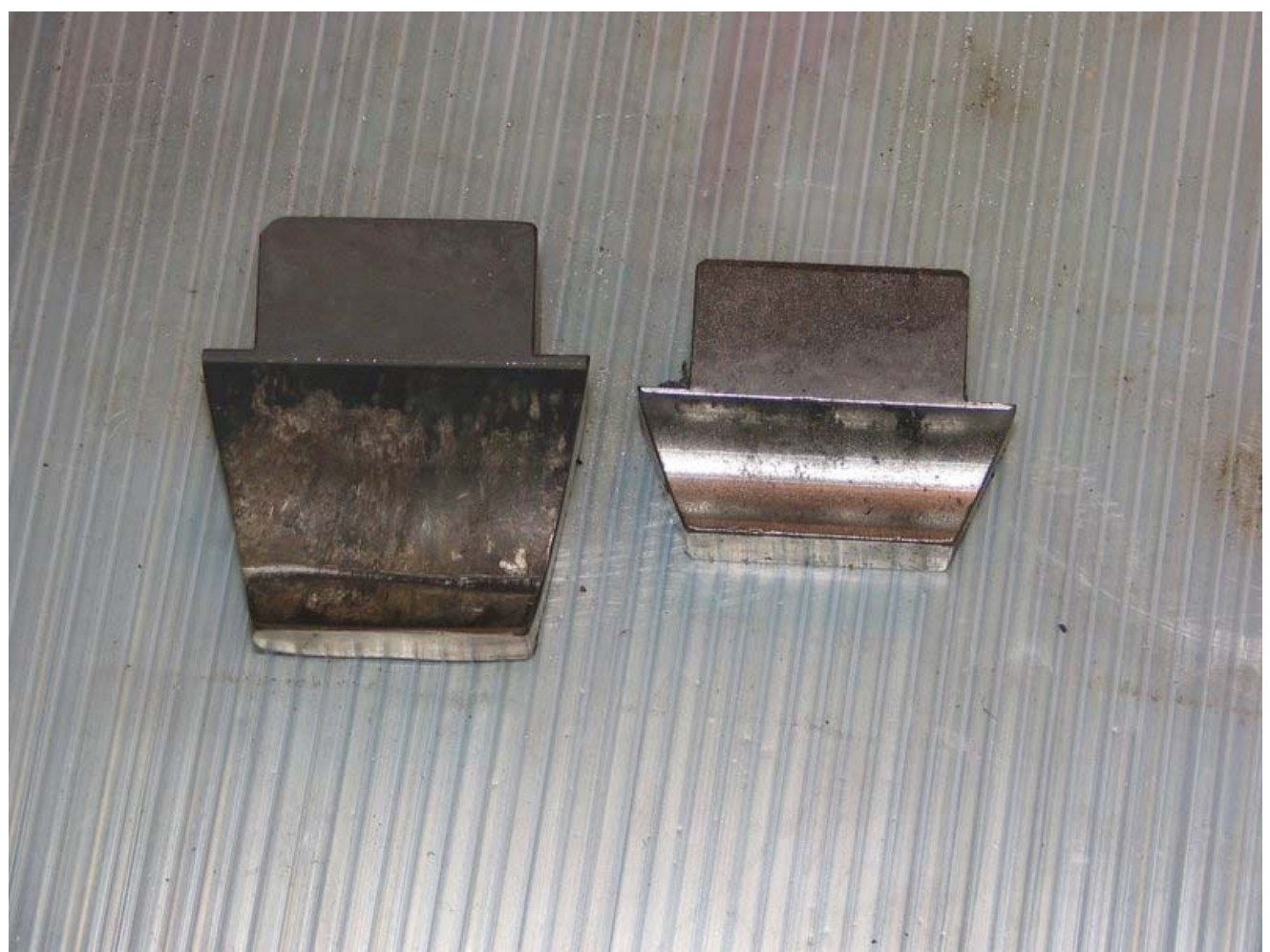

This shows the new tooth design, on the left, and the old design on the right. The new design has a much larger "bite" and can grab more of the carpet and pull it into the system. The rotor is smaller and has fewer teeth. 


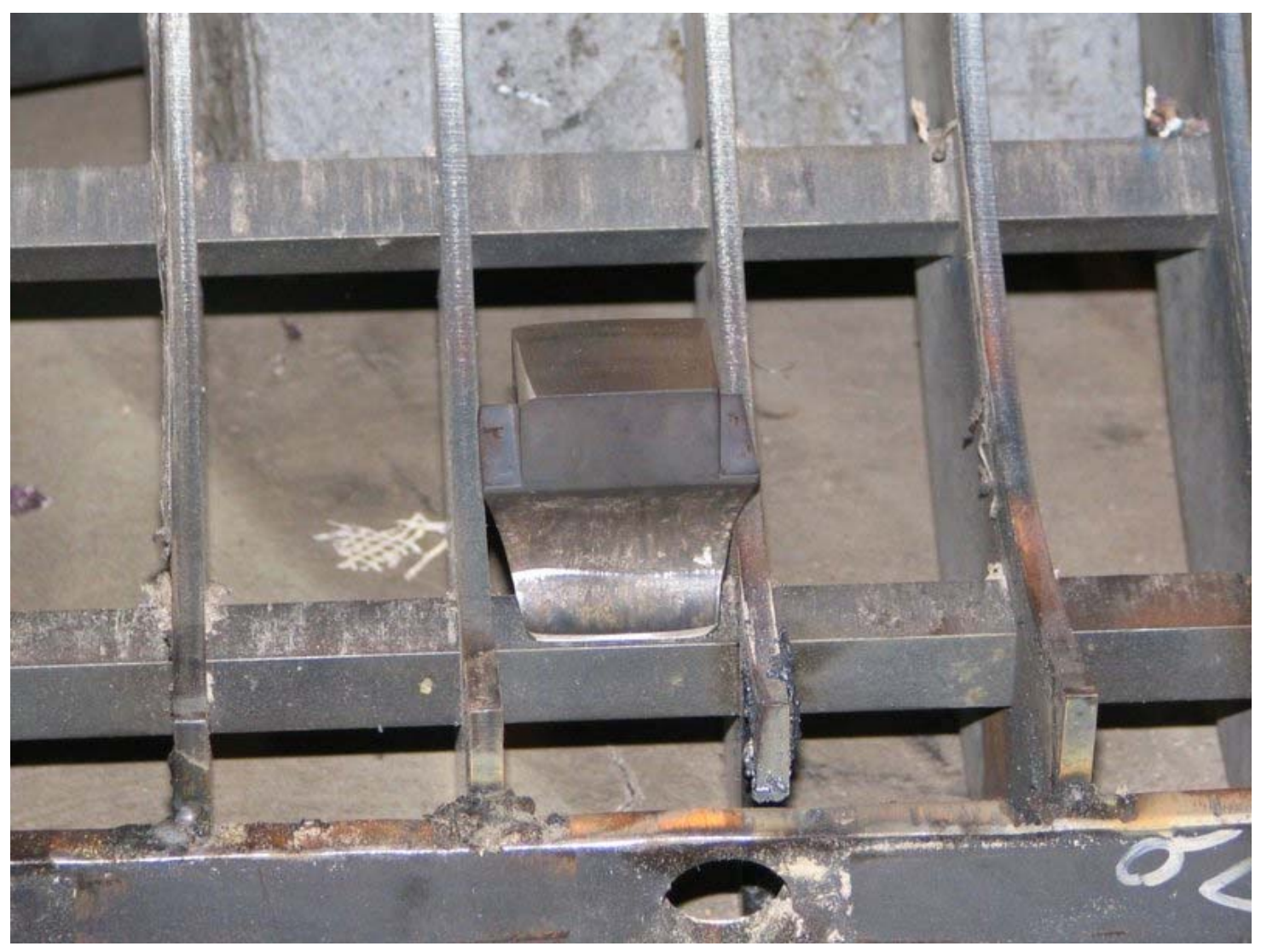

This picture shows a close up of the new tooth design and the screen design. The screen is designed to fit on the exit of the machine. The fit of the tooth into the screen means that the "strings" that connect pieces of the carpet together are less likely to remain un cut. This reduces the chances of the kiln feed system jamming on the material. 